\title{
La democratización de los espacios regionales y el trabajo político de la organización campesina en Colombia
}

\author{
Diego Fernando Silva Prada
}

Universidad Minuto de Dios, Bogotá, Colombia. Email: silvaprada@yahoo.es

\begin{abstract}
Resumen: El artículo pretender mostrar y analizar las formas de acción colectiva de la Asociación de Trabajadores Campesinos del Carare (ATCC), en cuanto actor social y político de la región del Magdalena Medio colombiano. Las lógicas de acción desarrolladas nos conducen a señalar a la organización campesina como una forma de potenciar la dimensión política de los colectivos al ser constructores de procesos de democratización de la territorialidad regional. La dinámica campesina propuesta incluye a los distintos actores armados del conflicto, los cuales han impuesto históricamente lógicas de exclusión y muerte sobre la población civil. Y esta inclusión se basa en la necesidad de la convivencia con todos los constituyentes sociales en un proyecto político de largo aliento.
\end{abstract}

Palabras clave: Organización campesina, democratización, territorialidad, participación, resistencia civil.

\section{The democratization of regional spaces and political work of the peasant organization in Colombia}

Abstract: The article aims to show and analyze the forms of collective action undertaken by the Association of Rural Workers of Carare (ATCC), as social and political actor in the colombian Magdalena Medio region. The logics of the developed action leads us to point out t the peasant organization as a way of enhancing the political dimension of the groups to be builders of democratization of regional territoriality. Rural dynamics proposal includes the various armed actors in the conflict, which have historically imposed exclusion logics and death of civilians. And this inclusion is based on the need for coexistence with all the social constituents in a long-winded political proyect.

Key words: Peasant Organization, democratization, territoriality, participation, civil resistance.

\section{A democratização dos espaços regionais eo trabalho político das organizações dos camponeses na Colômbia}

Resumo: O artigo tem como objetivo mostrar e analisar as formas de ação coletiva da Associação dos Trabalhadores Rurais de Carare (ATCC), como ator social e político na região do Magdalena Medio da Colômbia. A lógica da ação desenvolvida nos leva a indicar a organização camponesa, como uma forma de reforçar a dimensão política dos grupos para ser construtores de democratização da territorialidade regional. A dinâmica rural proposta inclui os diversos atores 
armados do conflito, que, historicamente instalaram lógicas da exclusão e morte sobre os civis. E essa inclusão se baseia na necessidade de convivência com todos os componentes sociais em um projeto político de longo fôlego.

Palavras-chave: organização de camponeses, a democratização, territorial, participação, resistência civil.

\section{Formación de sujetos políticos y luchas sociales como respuesta a la formación regional del Magdalena Medio}

El presente texto pretende indagar en ese otro lado del relato histórico que ha constituido la nación colombiana, el cual ha pasado inadvertido e invisibilizado en múltiples oportunidades. Esta historia hace parte de la genealogía de las resistencias sociales y de las luchas de las clases menos favorecidas en Colombia. Esas otras historias “menores” han sido silenciadas bajo la estridencia que producen los grandes acontecimientos políticos o desvanecidas por las lógicas institucionales de racionalización de la vida colectiva, con lo cual parece haberse perdido el significado del trabajo que cientos de hombres y mujeres han realizado durante décadas enteras por transformar, desde objetivos democratizadores y de justicia social, las estructuras de las sociedades en las que habitamos.

En esta primera parte del texto intentaré mostrar algunas experiencias históricas que justifican la caracterización de la región del Magdalena Medio como un espacio de luchas emancipadoras y de surgimiento constante de sujetos políticos colectivos. La intención es hacer ver que la región ha tenido una gran cantidad actores de la sociedad civil que han intentado reapropiarse de los espacios y de los territorios que actores militares e intereses económicos externos han tomados como propios, desde imperativos de explotación, dominación y acumulación de capital. En la segunda parte, presentaré la experiencia de surgimiento de la Asociación de Trabajadores Campesinos del Carare (ATCC), desde la definición de demandas pacifistas y el derecho a la defensa no armada, así como la creación de una voz propia frente de los actores armados de la región del Carare, en el departamento de Santander. La tercera parte la dedicaré a señalar el tipo de acciones colectivas más importantes puestas en marcha como estrategias de sobrevivencia dentro del conflicto armado y el papel central que ha tenido la constancia de los diálogos con todos los actores armados en un territorio incluyente para todos. La cuarta parte se centrará en ver la importancia de la dimensión económica y los proyectos productivos realizados por la asociación, así como la entrada de la economía cocalera y los efectos negativos producidos en la asociación campesina. Finalmente, señalaré la riqueza de la experiencia asociativa campesina al mostrar cómo, contrario a lo que pudiera esperarse, la reproducción de las resistencias sociales mediante la creación de nuevas organizaciones son un signo alentador de la salud que gozan este tipo de luchas políticas. Más allá de la definición a la cual estamos adaptados la mayoría de entender la política como el reducido 
espacio electoral y de las elites que controlan el poder de las decisiones administrativas, la ATCC nos ha ensañado cómo su función política ha consistido en la defensa de los espacios locales, en cuanto territorios en los que el bien común depende de la participación directa de sus constituyentes.

Las formas históricas de apropiación del territorio han desbordado los intentos de sectores y de actores económicos y políticos que han pretendido construir las regiones homogéneamente e integrar a sus pobladores en un modelo de desarrollo agroindustrial moderno, altamente inequitativo y con el constante recurso a la violencia, tanto legítima como ilegítima. Desde un inicio, esto es, desde que se tiene registro documental, el Magdalena Medio fue elaborando tramas de significación emancipatorias con respecto a la identidad colectiva de sus pobladores. Este imaginario colectivo se fue nutriendo de acontecimientos que mostraban la capacidad de las comunidades de negarse a la imposición de las voluntades ajenas y a los intereses foráneos.

La edificación de este ethos basado en la resistencia social y la rebeldía tuvo una de sus líneas más marcadas en la tradición ancestral de quienes, en "un principio", ocuparon las áreas bajas del departamento de Santander: los pueblos originarios Yariguíes, Carares y Opones. Estos pueblos eran cazadores y recolectores nómadas y fueron famosos por su capacidad de resistencia ante las múltiples incursiones de los encomenderos españoles y los intentos de fundación de asentamientos; temidos por el uso de dardos y flechas envenenados, llegaron incluso a comprometer el desplazamiento y el comercio entre Santa Fé de Bogotá, la capital del virreinato de Nueva Granada, la ciudad de Vélez y el puerto de Cartagena de Indias, para el siglo XVII. ${ }^{1}$ Uno de los personajes que pasó a la historia como símbolo de la resistencia indígena fue el cacique Pipatón, el cual sigue estando presente en la memoria de los habitantes de Barrancabermeja. Unificador de las etnias Yariguí y Carare, el cacique se convirtió en una leyenda de rebeldía al escapar de las autoridades españolas luego del cercenamiento de sus talones y de seguir luchando por más de diez años contra los colonizadores.

Esta trama basada en el imaginario de la resistencia se fue nutriendo, así mismo, con el levantamiento de los Comuneros, primer movimiento campesino del que se tenga conocimiento en Colombia, para el año de 1781 y, en especial, con las figuras de José Antonio Galán y de Manuela Beltrán. Antecedente del proceso de Independencia, el levantamiento popular se produjo a partir de las medidas estipuladas en las reformas borbónicas que dictaminaron el aumento de los impuestos en el tabaco, el algodón y el aguardiente en las provincias del Nuevo Mundo. La reacción coyuntural que reclamaba, en un principio, un "buen gobierno" (García Naranjo, s/f), preservando la figura de la monarquía española, terminó en un movimiento de reivindicación de los esclavos, indígenas y mestizos, y sobre todo, de libertad para los negros y no pago del tributo indígena. Luego de una travesía por el Magdalena Medio que le lleva a la liberación de cientos de esclavos negros de distintas haciendas y de formar tumultos en otras poblacio- 
nes de Cundinamarca, Galán es apresado, ejecutado y su cadáver desmembrado por las autoridades coloniales en el año de 1782. No obstante, Galán es un símbolo de lucha que sigue estando presente en el departamento de Santander, el cual ha sido retomado por distintos movimientos sociales. ${ }^{2}$

En tanto que frontera abierta, el Magdalena Medio fue, de igual manera, una amplia zona de recepción de población que huyó reiteradamente de los distintos tipos de violencia por las que pasó la República desde su fundación. Lugar de refugio, sobre todo para liberales perseguidos por los gobiernos conservadores, la región se fue conformando como espacio de libertad, en el sentido de oportunidad para no estar atado a las instituciones estatales o al dominio partidista y, a su vez, en el sentido de espacio de reconocimiento entre iguales que se hicieron a una identidad mediante las luchas dadas por el mejoramiento en las condiciones laborales y de vida. Desde esta segunda dimensión, gran parte de las respuestas generadas a causa de la llegada de actores económicos extranjeros estarán arraigadas en la conformación de las primeras organizaciones de carácter obrero, esto es, el primer sindicato obrero industrial del país: la Sociedad Unión Obrera, rebautizada en 1934 como Unión Sindical Obrera (USO). Fundada en 1923, la Uso fue constituyéndose como el principal actor social de la región, el cual sintetizó las demandas de una nueva clase de trabajadores, valiéndose esencialmente de las huelgas como instrumento de presión y de negociación laboral. A partir del apoyo dado por el entonces PSR, Partido Socialista Revolucionario, la huelga de 1924 será el comienzo de una larga lista de movilizaciones obreras en las que las demandas de mejoramiento de las condiciones de trabajo conducirán poco a poco hacia la politización del sindicalismo y hacia la adopción de una política de nacionalización de los recursos naturales (Romero, 1994).

Uno de los resultados más visibles, luego de años de movilizaciones, fue la nacionalización de la explotación petrolera, con la creación de la estatal Empresa Colombiana de Petróleos, (Ecopetrol), en 1951. Esta politización del movimiento obrero será más adelante, hacia los años 60 y 70, la generadora de la imbricación con grupos guerrilleros, sobre todo como apoyo estratégico con frentes del Ejército de Liberación Nacional (E.L.N). Sin embargo, para los años posteriores, años en que el fenómeno del paramilitarismo tomará fuerza, esta conexión entre sindicalismo petrolero y guerrillas izquierdistas representó la oportunidad del ataque indiscriminado hacia los líderes obreros y la criminalización de la protesta social, así como la aplicación estratégica de la proclamación constante de la ilegalidad de las huelgas.

Alrededor de la Uso y de otros sindicatos obreros, nuevos sujetos colectivos irán tomando fuerza desde el objetivo de llevar a cabo sus luchas reivindicativas y de reapropiación de la región. Igualmente inspiradas por el PSR, luego Partido Comunista (P.C), las Ligas Campesinas de los años 1920 fueron el antecedente más claro de los primeros intentos de organización campesina nacional. Tales intentos se generaron entorno a la figura de la hacienda como forma productiva. ${ }^{3}$ Hay que recordar en este 
punto que la hacienda se encontraba en Colombia en un momento de declinación y de confrontación con nuevas formas de producción industrial. El problema con el que se enfrenta la continuidad de la economía hacendaria hacia comienzos del siglo XX es que las nuevas élites industriales y comerciales "tratan de ampliar el mercado interno de mano de obra y de mercancías”, mientras que "la hacienda perpetúa patrones de producción y consumo muy restringidos.” (Bejarano, 1987: 42). Así es como, por un lado, la hacienda continuó teniendo sujeto a un número importante de población campesina en condiciones de aparcería y terraje y, por otro lado, la oferta laboral empujaba a cada vez más personas hacia formas de producción asalariadas, de carácter obrero y urbano.

Dentro de estas tensiones, las principales demandas de jornaleros y peones agrícolas estarán dirigidas hacia el mejoramiento de las condiciones de trabajo, consistentes en el: “pago de las mejoras a los arrendatarios, indemnización en el caso de expulsión de las haciendas, mayor participación en las cosechas, supresión de formas de renta en servicio o especie, mejor alimentación y ropa de trabajo adecuada.” (Tobasura, 2006: 12). No obstante, en el tránsito de los años 20 a los 30 se produjo el primer viraje en el repertorio de reivindicaciones del mundo campesino: de los reclamos por las condiciones de trabajo se pasó al cuestionamiento de la propiedad y el uso de la tierra. De esta forma, la presión por la tenencia y titulación se hizo sentir dentro y fuera de la hacienda. Las ligas campesinas y las ligas de colonos fueron, entonces, ese espacio de reconocimiento que unió desde peones y jornaleros hasta pequeños propietarios y arrendatarios que entraron a luchar por la titulación de tierras, tanto externas, de baldíos, como internas, fragmentando el latifundio hacendario. Aquí es donde comienzan a darse las primeras invasiones de tierras, en tanto que práctica campesina de reapropiación del recurso fundamental para su reproducción social.

Uno de los efectos de las luchas campesinas de estos primeros años se va a ver reflejado en las disposiciones legales tomadas por el estamento político al promulgarse la ley 74 de 1926, en la que se reconoce por primera vez en la historia del país la función social de la tierra, autorizándose además, la posibilidad de expropiación estatal de tierras no cultivadas. Este logro político del campesinado organizado se vio refrendado diez años más tarde al aprobarse la ley 200 de 1936, donde se estipulaba además la creación de jueces especiales para la resolución de los conflictos agrarios. ${ }^{4}$ Sin embargo, tales leyes generaron un efecto contraproducente, pues se dieron reiteradas expulsiones de campesinos por el miedo de los terratenientes a una mayor fragmentación de sus haciendas, vía expropiación estatal, y con el objetivo de llevar a cabo la reincorporación de la población campesina en condiciones de asalariados. La respuesta definitiva de los grandes terratenientes se da en el año de 1944 con la expedición de la ley 100, en la que se legalizan los contratos de aparcería y en donde se niega cualquier posibilidad de reforma profunda a la estructura de tenencia de la tierra. La cuestión agraria será así la configuradora fundamental de la conflictividad social en todo el país para mediados del siglo XX. La otra parte de la respuesta de los latifundistas y de la élite política conservadora consistió en el 
asesinato en 1948 del líder popular Jorge Eliécer Gaitán, desatándose así el periodo denominado como La Violencia. Cabe destacar que esta respuesta venía dándose desde el constante tensionamiento de las luchas entre campesinos y terratenientes por la tenencia y el uso de la tierra desde varios años atrás y que tal asesinato es el momento cumbre de la violencia bipartidista, el cual logró desarticular por varias décadas la organización campesina. ${ }^{5}$

$\mathrm{Al}$ igual que lo sucedido con los actores sindicales, las luchas campesinas estarán desde un comienzo fuertemente influenciadas por actores políticos como los partidos de izquierda. La primigenia organización campesina colombiana se entenderá como una experiencia política de base receptora de las líneas ideológicas de la Unión Nacional Izquierdista Revolucionaria (UNIR), fundada por Jorge Eliécer Gaitán, y por el Partido Socialista Revolucionario (PSR). No obstante, las mismas organizaciones campesinas, como la del Sumapaz, alcanzarán a fundar su propia representación política a través del Partido Agrario Nacional (PAN). Uno de los puntos más altos de la conciencia organizativa campesina se logra en 1942, con la fundación de la primera asociación de carácter nacional, en la figura de la Federación Campesina e Indígena. La relación con otros sectores sociales subalternos también llegó a ser, para este período, estrecha y solidaria, mediante la asistencia a congresos realizados por la entonces Confederación Obrera Nacional (CON) y por la Central de Trabajadores de Colombia (CTC). Se puede apreciar cómo desde un inicio la organización campesina se fue identificando como actor dentro de una red de actores sociales de base, aunque casi siempre a partir de propuestas y respuestas locales regionales, a excepción de la Federación Campesina e Indígena a la cual le permitieron una breve existencia nacional de sólo diez años de vida. ${ }^{6}$

De igual forma, junto a las luchas de obreros y campesinos, otros sectores sociales fueron tomando una voz propia en el intento de reapropiación de la territorialidad regional. Las luchas cívicas de usuarios de servicios públicos, de mujeres y de estudiantes fueron complementando históricamente el repertorio de demandas sociales y de derechos, con el objetivo de potenciar sujetos colectivos y promover una ciudadanía plena en la región. Así es como la Organización Femenina Popular (OFP) nace hacia 1972-73 a partir de la figura de los Clubes de Amas de Casa y por iniciativa de la Pastoral Social de la Iglesia Católica de Barrancabermeja, desde el objetivo de mejorar, primero, el entorno habitable y, más tarde, ser una radical oposición a la guerra y a la violencia en todos sus niveles: económica, política, social e intrafamiliar. ${ }^{7}$ Desde el trabajo básico del mejoramiento de las condiciones materiales de vida, referidas a las necesidades básicas de la población urbana y rural, hasta la conciencia política de la no-violencia, en articulación con la iniciativa "cadena de mujeres contra la guerra y por la paz", la OFP ha sido una: "resistencia al empobrecimiento y a la exclusión que se articula en la defensa de las libertades, los derechos, la vida, el salario y el trabajo (...) luchando por la reconstrucción de los espacios intervenidos por la especialidad de los actores armados." 
A la par de la consolidación del movimiento feminista, en el año 1975 se fue conformando un movimiento cívico que tuvo una gran influencia en la dinámica de conformación del puerto petrolero y lugares aledaños, desde la exigencia del mejoramiento en la prestación de los servicios de acueducto, alcantarillado, iluminación y el mejoramiento de vías, hasta la reivindicación de la calidad y la cobertura de la educación básica y la prestación de servicio de salud. Los paros cívicos de 1975, 1977 y 1981 permitieron de manera coyuntural el nacimiento de asociaciones civiles como el Comité Cívico Popular, el cual se transformó en el Movimiento Cívico, Obrero y Campesino y éste en la Coordinadora de Solidaridad ya para la década del 80. La Coordinadora Popular de Barrancabermeja será la institución encargada de sintetizar todos estos esfuerzos de años de luchas sociales, al preparar y llevar a cabo el primer gran paro cívico por la vida en Colombia en abril de 1987. Meses más tarde surgiría la Corporación para la defensa de los Derechos Humanos (CREDHOS), con el respaldo de todo el sector social y sindical organizado y como iniciativa de la Coordinadora Popular. Con el transcurrir del tiempo, el común denominador de las organizaciones cívicas del Magdalena Medio fue la convergencia hacia demandas relacionadas con la cuestión de la construcción de paz y la limitación del poder de los actores armados en los ámbitos locales. Esta paz se fue nutriendo de una concepción amplia en la que cabían tanto los diálogos y la concertación con dichos actores, como todas las cuestiones relacionadas con el tema del desarrollo y el bienestar económico de la población.

Podemos apreciar de esta forma cómo la región del Magdalena Medio se fue constituyendo lentamente, sobre todo en el trascurso del siglo XX, en una territorialidad signada por las tensiones sociales entre actores e intereses contrapuestos, desde la dinámica de la apropiación y la reapropiación, la negación y la afirmación dialéctica de identidades, modelos de desarrollo económico y formas de participación políticas excluyentes/incluyentes. A pesar de la diversidad de formas organizativas y de identidades derivadas de éstas, las cuales representaron en múltiples ocasiones falta de unidad, la identidad campesina sigue teniendo un peso fundamental en la conformación de la región y en la concepción territorial, a pesar de la inobjetable presencia y significación del factor obrero-petrolero urbano. Como diría Archila, el "peso de lo campesino", sigue siendo uno de los núcleos principales en la representación colectiva de esta región que se ha pensado como espacio reapropiado de las resistencias sociales, como lugar de emancipación política y de creación de alternativas económicas. Necesitamos ahora adentrarnos en las prácticas concretas que las luchas campesinas han venido desarrollando, con los objetivos de comprender la profundidad del fenómeno organizativo y reconstruir el sentido de sus dinámicas emancipatorias, para lo cual hemos tomado como estudio de caso una de las más representativas asociaciones de campesinos del Magdalena Medio: La Asociación de Trabajadores Campesinos del Carare (ATCC). ${ }^{9}$ 


\section{El nacimiento de la Asociación de Trabajadores Campesinos del Carare (ATCC) o el derecho a la defensa no armada}

La región del Carare-Opón, en el sur del departamento de Santander y al sur del Magdalena Medio, arribó en el año de 1987 a uno de los momentos más álgidos de la violencia política en toda su existencia. Desde finales de los años 70 la población civil experimentaba el constante asedio e intimidación de los diferentes actores armados. A mediados de abril de ese año, el capitán del Ejército Mauricio Betancourt definía el imperativo militar dado a los campesinos del Carare-Opón, el cual se basó en que: “en el término de 10 días optaran por unirse a cualquiera de los grupos armados, armarse en autodefensa, abandonar la región o morirse.” 10 Como se puede deducir de este mandato autoritario por parte de las fuerzas militares, el espacio y la territorialidad campesina se encontraban en aquel entonces atravesados por actores armados de todas las tendencias ideológicas. Los frentes 11 y 23 de las FARC venían dando una fuerte pelea por el dominio de esta región, la cual implicaba el hacerse a un corredor estratégico que permitía la salida al río Magdalena, con lo cual se tendría finalmente acceso al mar Caribe. Los paramilitares agrupados con el nombre de M.A.S, los "macetos" como se les llamó en la zona, venían "subiendo" desde su lugar de creación en el departamento de Boyacá, en expansión de su influencia hacia regiones con fuerte presencia guerrillera para realizar la estrategia de limpieza de zonas "rojas", tratando de dejar "sin agua al pez" como ellos mismos denominaban la arremetida contra la población civil afecta a la guerrilla. Por su parte, el Ejército se encargaba por todos los medio de concretar las políticas de militarización estatal del campo que desde el año 1977 empezaron a aplicarse como fórmula de lucha contrainsurgente, la cual, como ya se dijo, fue refrendada por medio de la adopción del famoso Estatuto de Seguridad del presidente Turbay Ayala, un año más tarde. ${ }^{11}$ Y en el centro de la escena, la población civil campesina que por múltiples y diversas circunstancias se fue involucrando poco a poco en el conflicto armado.

La ausencia de instituciones sociales del Estado y la no resolución de las necesidades básicas de la población (servicios de acueducto, alcantarillado o la implementación de puestos de salud y la construcción de vías), así como la desproporcionada fuerza con la que irrumpían los actores armados estatales, llevaron de alguna manera a la adopción de la idea de justicia social desde la que los grupos guerrilleros lograron insertarse en la región. El slogan "el rico será menos rico y el pobre será menos pobre”, implicó la puerta de entrada en la participación y colaboración del campesinado con las fuerzas guerrilleras, las cuales se arrogaron la representación de los intereses de quienes casi siempre habían estado marginados de las riquezas rurales. No obstante, el costo de esa gradual decisión colectiva implicó el involucramiento en una dinámica de guerra que trajo la muerte a aproximadamente unas 580 personas en el lapso de 5 años, de 1982 a 1987. (Ferreira, 2008). Al igual que en otros zonas del país, la violencia política 
fue la constante dinamizadora de los procesos sociopolíticos durante esos años en la región del Magdalena Medio colombiano. Como se demostró más arriba, todos los actores armados fueron construyendo un tipo de territorialidad basada en relaciones autoritarias y los intereses de la mayoría eran disputados por actores externos a la comunidad campesina.

La singularidad de la respuesta que fue surgiendo de la comunidad del Carare, asentada en el corregimiento de La India, municipio de Landázuri, se basó en ir más allá de las cuatro alternativas que el capitán Betancourt sintetizaba. En palabras del líder comunitario Luís Carlos Restrepo, se afirmó: "ni nos vamos, ni nos morimos, ni les seguimos colaborando a ningún grupo, ni nos armamos."12 Comenzó a gestarse, entonces, lo que el pastor adventista, don Simón Palacios, acertó en llamar la "campaña silenciosa”: el ir mirando posibilidades de acción colectiva a través del diálogo personal y en voz baja, “de uno en uno”, para responder al ultimátum militar, puesto que estaba prohibido por el Ejército cualquier reunión que excediera las tres personas.

La entrada al pueblo de La India por parte de los “macetos", días más tarde, permitió hacerle ver a la comunidad cuán frágiles y desprotegidos estaban precisamente de esas fuerzas guerrilleras a las cuales les brindaban colaboración y que no pudieron responder ante la incursión de sus enemigos en territorio propio. Esa fue la excusa perfecta que permitió tomar la fuerza suficiente para que, en cabeza de los líderes Josué Vargas, Simón Palacios, Ramón Córdoba, Héctor Piñeres, Excelino Ariza, Salomón Blandón, Manuel Serna, Oswaldo Perea, Fernando Chávez y Saúl Castañeda, se movilizaran al encuentro de los jefes guerrilleros del frente 23 de las FARC. Esa primera gran reunión con la guerrilla fue el ladrillo fundacional de la Asociación de Trabajadores Campesinos del Carare (ATCC), en ella el silencio y el miedo se transformaron en la conciencia política de la primera comunidad campesina de paz de Colombia:

"Frente a los 3 comandantes nosotros les dijimos: señores guerrilleros nosotros les pedimos esta invitación porque ya estamos cansados con lo que ustedes están haciendo con nosotros. ¿Ustedes recuerdan con qué política llegaron a esta región? ¿La política no era que el pobre iba a ser menos pobre y el rico menos rico? ¿Y hoy dónde está el Carare? ¿Cómo está? Solo, abandonado, sólo se ven viudas y huérfanos, porque ustedes mismos tienen arruinados a esta comunidad que los ayudó. Luego vino Josué y les dijo: De aquí en adelante señores cuenten con que ustedes no reciben beneficio de ningún campesino. Y el campesino que los ayude arrastrará las consecuencias, pero no la paz." ${ }^{13}$

Según cuentan las fuentes orales, la reunión finalizó con las siguientes palabras del mismo Josué Vargas Mateus:

"Comandantes de las FARC, ya son las 5 de la tarde, no hemos llegado a acuerdos y tenemos que irnos, pero les vamos a decir lo siguiente: hasta hoy el Carare les sirve a ustedes, y de ahora en ade- 
lante los que mandan en esta región, aquí, somos nosotros los campesinos, y ustedes ya no tienen más hermanos aquí. Hasta hoy mandan ustedes, y de hoy en adelante, ni un campesino más muerto, no les vamos a trabajar más."14

Ante la sobrevivencia del encuentro y la respuesta positiva de los comandantes guerrilleros, dada días más tarde, basada en el no involucramiento de la población civil en el conflicto y la no demanda de ayudas, los campesinos del Carare comprendieron que debían hacer lo mismo con los otros actores armados, Ejército y paramilitares, si querían construir un verdadero status de civilidad y neutralidad dentro de la disputa por el territorio que estaban viviendo. La reunión sostenida, dos meses después, con el general de las fuerzas armadas de toda Colombia, Manuel Jaime Guerrero Paz, y otros once generales, arrojó un balance aún más positivo. El resultado fue, según cuentan testigos, el reconocimiento abierto por parte del Ejército de las formas de acción pacíficas y el cese de las extralimitaciones de la fuerza sobre la población civil: "El general dijo: si todo el mundo reaccionara como están reaccionando ustedes, el país cambiaría. Cuenten con nosotros, cuenten conmigo para colaborarles.”15 Así mismo, los demás coroneles expresaron su sorpresa afirmando:
“en ninguna parte de Colombia hemos oído eso, esta es la única región que hemos escuchado tal postura. Esto va a salir por la noti- cias porque en ninguna parte de Colombia los campesinos renun- cian a la guerrilla y ahí están las bases para que recurran a noso- tros." 16

De esta forma surge la experiencia de construcción de paz desde la organización campesina autónoma más antigua del país ${ }^{17}$. Desde la consigna de lucha por: “el derecho a la vida, la paz y al trabajo", la ATCC se fue convirtiendo en organización defensora de la comunidad del Carare, a través de una filosofía de acción fundada en la No-violencia activa, en la que la comunidad es propietaria del derecho de ser neutral y quedar por fuera del conflicto armado. Así mismo, este derecho se expresa en todo el territorio de influencia de la asociación, el cual es de unas 94.126 hectáreas pertenecientes a los municipios de Cimitarra, Landázuri, Bolívar, El Peñón, Sucre y La Belleza. Como se lee reiteradamente en las pancartas que señalan la pertenencia a la asociación de cada vereda: el "con esta comunidad no cuenten para la guerra” ha sido un escudo simbólico de neutralidad para combatir a los actores armados que siguen transitando por la región.

La paz entendida desde el principio de la no-violencia activa se plasmó desde el comienzo con el primer comunicado público distribuido en todo el territorio del Carare-Opón como una muestra de la identidad y de la existencia efectiva de la asociación. En éste se podía leer:

"Nosotros, los habitantes del Carare, Santander, manifestamos el rechazo a todas las formas de violencia. Tantos años de violencia sin logros positivos para el país han demostrado suficientemente 
que las armas no son la solución a los problemas sociales que vive el pueblo colombiano. Por lo tanto, hemos optado por el camino de la No-violencia activa, que es:

1. Denuncia permanente de cualquier violación de los derechos humanos.

2. Entender que la cultura es la mejor respuesta a la barbarie.

3. Organización de las comunidades para autogestionar el desarrollo a través de procesos democráticos.

4. Individual y colectivamente negar todo tipo de apoyo a cualquier forma de violencia.

5. Buscar permanentemente el diálogo, el entendimiento y los acuerdos para concertar con las diferentes formas de opinión, salidas políticas democráticas como respuesta a la problemática social.

6. Buscar la vinculación activa tanto de organismos gubernamentales como de los no gubernamentales de carácter nacional y la de organismos internacionales que respeten la soberanía nacional y la autonomía de las organizaciones democráticas.

7. En fin, luchar por que la paz y la democracia dejen de ser unos conceptos vagos convirtiéndolos en realidades concretas.”18

En el comunicado podemos apreciar el énfasis puesto a la cuestión de la paz y la democracia como elementos centrales de sus luchas regionales, así como la ausencia de la cuestión histórica de una mejor distribución de la tierra. No obstante, la paz se irá entendiendo a través del componente del desarrollo agrario y de los programas económicos de proyectos productivos solidarios y comunitarios. Por el momento hay que decir, que esta política de noviolencia activa, a pesar de las inmensas dificultades para seguir convocando y dialogando con todos los dirigentes de los grupos armados locales, le significó a la región una paz de más de 30 meses, donde ningún campesino fue asesinado, donde se respetó la neutralidad de la población campesina y donde bajaron los índices de violaciones de derechos y las arbitrariedades por parte del Ejército. ${ }^{19}$

\section{Repertorios de la acción colectiva campesina: resistencias civiles y la persistencia de los diálogos de paz}

La fortaleza política fundamental de la asociación reside en el repertorio de acciones colectivas puestos en marcha por la ATCC, las cuales se ha fundamentado principalmente en el diálogo y la concertación permanente con los actores armados, desde tres niveles complementarios. Por un lado, como vimos, los líderes de la organización se dirigieron a los altos mandos de los ejércitos legales e ilegales para lograr el reconocimiento como actores civiles y neutrales dentro del conflicto en la región. A los campesinos del Carare no les tembló la voz para hablar con los mayores representantes del Ejército, de las FARC y de los paramilitares a los que pudieran acceder. Con cada uno de ellos expusieron sus argumentos. Como se afirma: 
"nosotros hemos tenido la capacidad de desarmar a la guerrilla, no de quitarles los fusiles, pero si de desarmarlos desargumentándolos, porque sus argumentos se caen ante nosotros. Nosotros hemos llegado a muchas altas esferas y ha sido posible sentarnos y hacer respetar nuestro espacio.”20

Los “grandes diálogos” como podrían denominarse, por ser diálogos con altos representantes del nivel institucional, se dieron en los primeros años de vida organizativa con el fin de ser reconocidos como una voz propia en la región, en "nuestro espacio", el cual no era el espacio armado, sino el espacio campesino que se afirmaba en su condición civil mediante la asociación de iguales y la organización de las comunidades. Y en este gran primer paso, estuvo en juego la vida de todos aquellos que tuvieron el coraje de hacerle frente a una violencia política que se había convertido en constante, en forma de reproducción social en la región. ${ }^{21}$ Esos diálogos con las altas esferas tuvieron que ser, una y otra vez, realizados con el fin de recordar los acuerdos a los que se había llegado y con el objetivo de que en los distintos ejércitos imperara una coherencia de acción militar en relación con la población civil.

El segundo nivel complementario está referido a lo que los ciudadanos de la región llamaron las resistencias civiles, especies de "avanzadas" colectivas realizadas por el río o camino adentro del monte para impedir que algún grupo armado impusiese una situación de aislamiento o de involucramiento de alguna vereda o territorio en la disputa militar. En varias ocasiones, esta situación se presentó a raíz del bloqueo de alimentos por parte del Ejército o de los paramilitares como estrategia de corte de suministro de víveres para las zonas de posible presencia guerrillera. Ha sido, además, una forma participativa directa de corroborar la coherencia e identificación de la comunidad con la organización, pues en muchas oportunidades el argumento de los actores armados se basaba en que la junta directiva de la ATCC tenía posturas no compartidas por la mayoría de la población campesina. Ante eso, se les demostraba mediante una gran movilización la voluntad del "pueblo":

“Eso cuando arranca es de aquí para arriba motor, motor y motor. Y se va todo el mundo. Es la presión del pueblo. No para decirles es que ustedes se tienen que ir. No, sino para decirles estamos acá para que nos digan ¿qué es lo que hemos hecho mal? ¿Por qué nos tienen que castigar de esa manera? ${ }^{22}$

"Río arriba o hacia adentro hemos tenido que caminar mucha horas, subiendo y bajando valles. Así es que nos movilizamos todos. Es un mecanismo de presión para demostrar la voluntad de la comunidad. $\mathrm{Y}$ ese es el mecanismo en este país, lo hacemos de manera pacífica, no usamos violencia. (...) Nuestra resistencia se basa en que nosotros somos autónomos en nuestra región, a nosotros nadie nos viene a imponer las reglas como ciudadanos colombianos.”23 
Es fácil darse cuenta de lo cercano que está la cuestión de la participación en los asuntos colectivos con respecto a la cuestión de la solidaridad. Para la comunidad campesina organizada, la participación política, esto es, las acciones que deciden sobre el bienestar del colectivo, no se pueden escindir de las prácticas de fraternidad e identificación con los otros. El significado de participar para el actor campesino está directamente relacionado con el defender el bien de la mayoría, ya sea salvando la vida de ese otro que tiene una ideología distinta o ya sea movilizándose para enfrentar el poder de las armas con el fin de restituir el orden desde la civilidad. No obstante, aquí podemos ver el espacio y la distancia que existe entre la comunidad y la organización. Lo que puede llegar a conectar a la organización con la comunidad es la participación en acciones colectivas. La comunidad del Carare está compuesta por múltiples sectores socioeconómicos como los comerciantes, transportadores o pequeños industriales de la madera, los cuales, en su gran mayoría, no han apoyado la propuesta de construcción regional de la ATCC. ${ }^{24}$

En un tercer nivel se practicó una muy acertada política de concertación para salvar puntualmente la vida de las personas que por uno u otro motivo se habían visto involucradas como auxiliadores de alguno de los bandos, no importando que fueran o no asociados. La ATCC se fue convirtiendo en institución promotora de resolución pacífica de conflictos y de la convivencia. En palabras de dos sus líderes:

"Se hace todo lo humanamente posible para poder negociar la vida de esa persona. Cuando la cosa está muy grave, les decimos dennos la oportunidad de llevarnos a la persona para otro lugar. A mucha gente se le ha salvado la vida de esa manera (...) nos movilizamos lo más rápido posible para dar la oportunidad de defenderse a la persona"25

Este tipo de acción colectiva de intercesión o de salvamento de la vida personal se constituyó en una de las más eficientes herramientas de defensa contra la intransigencia que el conflicto armado generaba en el nivel local de relaciones interpersonales. Gracias a éste, como dicen los asociados, se logró salvar la vida de muchas personas en la zona. Si es que ha existido algún método para llevar a cabo estas prácticas de concertación para el salvamento de la vida, se podrían resumir en lo que un asociado denominó como recurso de “desactivación” de la situación de violencia, consistente en "bajarle la temperatura" a la situación, valiéndose del escuchar las razones del otro y el recordar los acuerdos a los que los "jefes" de los bandos en disputa habían llegado a aceptar. ${ }^{26}$

\section{Los proyectos productivos como defensa de la soberanía alimentaria y de la autonomía comunitaria}

La continuidad de las experiencias organizativas de la asociación estuvieron, por un lado, como ya desarrollamos, ancladas en la creación e 
innovación de acciones colectivas que involucraron a la población campesina y a población acompañante en la defensa de la territorialidad y, en últimas, de la apuesta social y política de los planes de desarrollo comunitarios. Sin embargo, en cuanto comunidades campesinas, la definición de proyectos económicos enfocados hacia cultivos tradicionales de sobrevivencia, soberanía y autonomía alimentaria, se fueron constituyendo en una segunda dimensión de la organización, igual de importante que la primera. A la par de las movilizaciones, resistencias civiles y los diálogos, los proyectos productivos de la ATCC han permitido la reproducción de la vida campesina en sus regiones como un modelo viable y sostenible, frente a un modelo económico agroindustrial modernizante y reductor de la diversidad agrícola.

En el Carare-Opón, para 1988 la ATCC fue la responsable de la definición de once frentes de trabajo comunitario como parte de un proyecto concertado para el mejoramiento de la calidad de vida de sus pobladores. ${ }^{27} \mathrm{El}$ primer frente era el concerniente a vías. La idea era poder construir unos 98 kilómetros de carreteras para la intercomunicación de las veredas, involucrando al Ejército en el desarrollo de la infraestructura local. El segundo, la adquisición de por lo menos 4 tractores para la mecanización de la producción agrícola. El tercero referido a la cuestión del mercadeo, donde se creara una tienda comunitaria para suministrar productos y eludir la cadena especulativa que existía hasta entonces, regular la distribución del plátano para evitar pérdidas y comprar tres desgranadoras de maíz para lograr, de igual manera, comercializarlo sin depender de intermediarios. El cuarto, la solicitud al estatal Servicio Nacional de Aprendizaje (SENA), para capacitación técnica agroindustrial. El quinto, un nuevo reasentamiento en la vereda La Pedregosa. El sexto y más ambicioso del fomento agrícola, donde se pudieran llegar a sembrar 2.800 has de cacao, 750 has de caucho y reforestación de 2.700 has, entre otras, en un lapso de 6 años. El siguiente, dirigido a la construcción y dotación de 9 escuelas faltantes. Más adelante la construcción de unas 150 soluciones de vivienda por coparticipación. El noveno frente, la muy necesaria construcción de por lo menos 3 puestos de salud. El décimo, realizar obras de alcantarillado y acueducto. Y el último, la construcción de un muelle para la protección del casco urbano de las aguas del Carare. ${ }^{28}$

A pesar de las buenas intenciones y de la amplitud de los proyectos, de este plan de desarrollo se pudieron concretar: la creación de la tienda comunitaria, con su respectivo ataque a la cadena especulativa de mercadeo, la construcción de un muelle escalonado y la puesta en marcha de una escuela por participación de la cooperación japonesa. Así mismo, se logró la compra de motores fuera de borda que vinieron a reforzar la comercialización de los productos. También fue posible la edificación de 3 molinos para el procesamiento de caña de azúcar y la producción de panela. La región se empezó a transformar, entonces, mediante una economía solidaria basada en el ataque a la especulación de las cadenas productivas. La nueva Cooperativa de Trabajadores Campesinos del Carare (CTCC) permitió el resurgimiento de la producción agrícola de cultivos tradicionales 
de la región como el caco, la caña de azúcar, el caucho, la yuca y el plátano. A la paz se le iba sumando el desarrollo económico. No obstante, las mayores debilidades en la realización de los proyectos fueron la falta de apoyo estatal a la pavimentación de las vías, la continuidad en el servicio médico y la no realización de los trabajos de acueducto y alcantarillado.

Pero con el transcurrir del tiempo, como fue comprobado oralmente, a la gente se le fue olvidando que la paz y el desarrollo eran una constante construcción participativa y que más allá de ella, la guerra y la muerte seguían esperando. Y como complemento, para los años 97-98, la siembra de coca fue penetrando en la región, a raíz de dos circunstancias. La política estatal de fumigaciones aéreas se intensificó en la región del sur de Bolívar y del Cesar, con lo cual los patrocinadores de los cultivos ilícitos se desplazaron hacia el Carare, promoviendo la coca como una opción económica. Y la segunda, la cual amerita un paréntesis, es que para ese entonces se había definido con toda su intensidad lo que se denominó como la "crisis semipermanente” del agro, a raíz de las políticas macroeconómicas de liberalización de la economía.

La apertura económica fue el nombre de la política que el gobierno de César Gaviria (1990-1994) promovió como estrategia de modernización acelerada del país. La apertura del mercado interno colombiano permitió la entrada de alimentos y productos extranjeros a bajos aranceles y en desigualdad de condiciones de competencia con los productos agrícolas nacionales. Las consecuencias que tuvo la política aperturista sobre el sector agrario se reflejaron al cabo de unos cuantos años en las siguientes y muy dicientes cifras:

“- Los cultivos semestrales pasaron de 2.5 millones de hectáreas en 1990, a 1.6 millones, en 1997.

- La reducción de las áreas sembradas en cultivos semestrales condujo a la pérdida de 119.600 empleos.

- En consecuencia, las importaciones crecieron a un ritmo anual del $26.8 \%$; pasaron de ser el $5.5 \%$ del PIB, en 1990, a ser el $46.9 \%$, en 1997. (...)

- La producción tuvo un descenso sin antecedentes: de las 130 mil toneladas de algodón exportadas por Colombia en 1975, se descendió a 4.707, en 1996, y a 497, en 1997 (Misión Rural 1998, 43).

- En Junio del año 2000, el país estaba importando seis millones de toneladas de alimentos, "ocho veces más que hace una década”(CGR).” (Fajardo, 2002: 5)

Como podemos apreciar, las políticas macroeconómicas se constituyeron en otra variable más dentro del conjunto de factores que determinaron el bienestar o el deterioro de las condiciones de la población del sector agrario. La apertura de la economía nacional llevó directamente a la destrucción de miles de puestos de trabajo e impulsó al cambio de cultivos legales no competitivos hacia cultivos ilegales que tuvieron en un principio capacidad de ganancia para las comunidades campesinas. Así es como los 
campesinos del sur del Bolívar, el departamento de Cesar y el sur de Santander fueron arrojados a cultivar la hoja de coca como recurso de sobrevivencia económica.

Esta situación condujo a un severo debilitamiento organizativo de la ATCC. La mayor parte de la comunidad fue dejando sus cultivos de pan coger, tras la idea ilusoria que producía el cultivo de la hoja de coca de una mayor ganancia y, por ende, de un mayor bienestar. Las consecuencias de la economía cocalera fueron aún mayores que cualquier ataque de violencia política armada. Para 1998, la organización se dividió entre quienes defendían el cultivo y quienes veían sus inconvenientes. La participación en la organización tuvo que ser, entonces, reducida a su mínima expresión a favor de aquellos que no adoptaban los cultivos ilícitos, ${ }^{29}$ pues éstos, dentro de la lógica y principios de la organización, desincentivaban la producción de otros cultivos, necesarios para el autoabastecimiento y la seguridad alimentaria de la comunidad campesina. Lo anterior llevó a un marcado detrimento de las prácticas de economía campesina tradicionales y junto a ello un debilitamiento de los valores como la solidaridad. Como dice uno de los líderes fundadores:

"Por la ambición de la plata muchos le voltearon la espalda a la ATCC, por irse a cultivar coca. En ese tiempo se vino el apogeo de la coca. Eso fue un virus. La coca iba complicando la vaina de la paz, por eso mucha gente aquí perdió la vida, por vincularse con la coca. La coca fomentó mucha violencia, con eso la gente se creía superior que el resto.”30

La economía cocalera fue un “disolvente” magnífico de la organización campesina, puesto que enfrentó la sobrevivencia personal-familiar de los asociados y no asociados contra las soluciones concertadas de una comunidad organizada en una asociación que no admitió la adopción de dicha economía ilegal.

Los avatares organizativos muestran hoy en día a una ATCC que viene saliendo de la etapa de debilitamiento producido por la economía cocalera, reconstruyéndose de nuevo a partir del fortalecimiento institucional, desde proyectos productivos como alternativa real para la región. Proyectos como la reactivación de la actividad de los molinos de caña, el de microhato ganadero de doble propósito y los cultivos de caucho están dirigidos hacia esa dimensión más débil que la comunidad ha percibido de la ATCC. ${ }^{31}$ Como lo señala su vicepresidente:

"Hay necesidad de reactivar todo ese sistema que se venía trabajando juiciosamente. Vienen los proyectos productivos como la fina integral campesina con la definición de dos o tres productos líderes, volver a reactivar la economía solidaria. Generar valor agregado a través de la transformación de esos productos líderes, entonces hay que pensar en la agroindustria, se podría decir, o miniempresas, donde podamos hacer una transformación a los productos y siem- 
pre como en la idea de lograr unos recursos más para los ingresos familiares." 32

Así mismo, se ha acogido la propuesta de la Comisión Nacional de Reparación y Reconciliación (CNRR), comisión mixta integrada por miembros del gobierno nacional, del Ministerio Público, representantes de la sociedad civil y representantes de las asociaciones de víctimas, como una estrategia para lograr reparar a la población víctima del conflicto. La falta de atención estatal en el aspecto social parece, así, estar subsanándose con la apertura de este proceso enmarcado en la ley 975 de 2005, llamada de justicia y paz, la cual permitió el desmonte de las principales estructuras paramilitares en el país.

\section{La reproducción de las resistencias mediante el nacimiento de nuevas organizaciones sociales}

A pesar de las debilidades y de los ataques, de los momentos bajos y de las divisiones internas, la dinámica organizativa de la ATCC ha llevado a que ese interés por lo colectivo produzca nuevas demandas, enriquecedoras del tejido social local. La asociación ha sido la partera de nuevas organizaciones, fundamentando así el principio el cual "una organización lleva a otras organizaciones”. Por ejemplo, la organización campesina abrió la perspectiva de la defensa de los derechos humanos, permitiendo la participación política de las mujeres. El colectivo Silvia Duzán y el grupo Mujeres en Acción han demostrado que las estructuras de violencia intrafamiliar y de género pueden ser combatidas mediante la asociación de sus iguales y el involucramiento en micro proyectos productivos como el de cría de cerdos o el de comercialización del plátano. ${ }^{33}$ A pesar de que la ATCC ha sido un espacio social de inclusión de demandas, las mujeres de la región sintieron la necesidad de formar nuevas organizaciones a partir del ejemplo que la organización matriz les dio. Los elementos estructurales y culturales del machismo no han podido ser desterrados y sigue siendo un problema en el desarrollo de las mujeres en la región:
“Acá hay mujeres muy valientes, que tiene una capacidad enorme, pero cuando llegan a la parte de demostrar lo que son ellas, les da temor. Esa autoestima está todavía baja, tiene todavía en la mente que ella no es capaz, porque desde niña se lo han inculcado. Es muy difícil salir de ese error. (...) Nos sentimos opacadas por el liderazgo masculino. El machismo en Colombia y en Santander, en cualquier organización no deja.”

Así mismo, una de las más exitosas experiencias de multiplicación organizativa campesina es la caracterizada por la Asociación de Desplazados del Carare (ASODECAR). En la actualidad, Asodecar le permite a 58 núcleos familiares continuar con proyectos de vida centrados en la economía campesina tradicional. Por medio de soluciones de vivienda, produc- 
ción de caucho, como programa a mediano y largo plazo, en combinación con la producción de alimentos para la defensa de la seguridad alimentaria como el plátano, la yuca y la producción piscícola, la población desplazada reencuentra un nuevo sentido de lo colectivo luego de la ruptura de los lazos comunitarios y territoriales.

Al igual que en la ATCC, en Asodecar la participación no deja de estar atravesada por dificultades que redefinen la naturaleza asociativa y las grandes limitaciones que tiene la democratización de la vida social. La condición del desplazamiento forzado, que en muchas ocasiones lleva en sí la continuación de anteriores desplazamientos o de desplazamientos transgeneracionales, podría hacer creer que la participación en este nuevo proyecto asociativo se efectúa sin mayores inconvenientes y con una mayor homogeneidad. Pero la realidad es que existen los mismos problemas y divergencias que en sectores campesinos no desplazados.

"No es tan fácil eso de la participación de todos y uno como líder créalo que yo no sé de donde saca tanta paciencia, tanta energía. Con la participación se reconocen, pero a veces prefieren no participar y quedar un poco relegados del proceso organizativo. Esto implica un esfuerzo muy grande para las personas. Pero como todos no tenemos la misma perspectiva, la misma conciencia." ${ }^{34}$

\section{El aporte de la ATCC a los procesos de democratización la vida social}

Más allá de los sistemas políticos electorales vigentes en Colombia y en América Latina y, porqué no decirlo, más allá de la idolatría y la necesidad de que todo sea pasado bajo el tamiz de la democracia, esa gran instancia contemporánea de legitimación de las acciones políticas, el ejemplo aportado por esta pequeña organización campesina nos muestra que democratizar significa, antes que nada, el poder de participar en la vida de una comunidad que necesita decidir sobre las cuestiones fundamentales de su presente, para que pueda llegar a existir un futuro más justo. En Colombia, ese presente-futuro está circunscrito, en muchas ocasiones, a las posibilidades de transformación y canalización el conflicto armado. La ATCC ha logrado canalizar e institucionalizar el conflicto mediante el diálogo y la concertación con los actores armados y en esta medida ha influido en la democratización la región del Carare Opón. Organizaciones campesinas como la ATCC le han otorgado al poblador rural la posibilidad de quebrar con el aislamiento que normalmente le ha impuesto la ley del silencio de la guerra y así restituir los lazos comunitarios rotos por la violencia. Y en esos lazos de reconocimiento/distanciamiento con la comunidad es donde se ha podido llegar actualizar la dimensión política de los sujetos. Entendemos así cómo la propuesta organizativa implica una repolitización de carácter democrático en la medida en que crea espacios de inclusión y de concertación en las cuestiones públicas locales. 
Esa democratización, en el sentido de ampliación participativa en los diferentes ámbitos de la vida social, tiene lógicamente sus límites. En el aspecto de la composición interna de la organización, la historia de la ATCC nos mostró que la participación necesita ser restringida en contextos de violencia política, en cuanto práctica estratégica de sobrevivencia. Igualmente, como fue señalado por la mayoría de las fuentes orales, participar implica un alto grado de compromiso a partir de condiciones materiales y culturales que a veces no están presentes en el medio social. La historia misma juega un papel decisivo y adverso cuando se aspira a transformar una comunidad marginada. Aquí es donde entendemos que participar no es cuestión simplemente del querer racional o de cálculos entre costos y beneficios. Las experiencias de barbarie y violencia cotidiana han llevado, en no pocos casos, a la producción de una subjetividad ensimismada en el sinsentido social y hastiada de cualquier tipo de promesa, de esperanza. En estos casos, ni la invocación democrática ni los discursos desarrollistas sirven. Simplemente, las promesas de la modernidad política perdieron la apuesta ante la experiencia de la muerte.

Contrariamente a lo que podríamos pensar con respecto al desarrollo y ampliación de las expresiones organizativas campesinas en contextos de alta tensión bélica e intereses transnacionales en juego, el nacimiento de nuevas asociaciones ha sido el resultado y la muestra de que las comunidades campesinas se siguen organizando y que tienen un alto grado de resistencia histórica. A pesar de la violencia política y económica que se sigue ejerciendo en el Magdalena Medio, las asociaciones campesinas se reinventan como colectivos defensores de los derechos humanos y como actores civiles y sujetos políticos con proyectos de región auténticos, constructoras y protectoras de una territorialidad democrática, donde todos los actores, civiles y militares, tienen cabida en el espacio.

La dinámica de la democratización en el mundo rural sirve para comprender que ésta es una batalla lo suficientemente compleja como para dar pronóstico alguno. Las libertades alcanzadas por las sociedades no están sujetas a leyes y las constantes pueden ser rápidamente interrumpidas por el juego azaroso de las relaciones de poder e intereses que mueven a las comunidades y a los sujetos. A momentos de relativa calma y de mayor participación, vendrán seguramente momentos de contracción de libertades y de violencia. La organización campesina es un claro ejemplo de que nada está ganado y de que lo que debería estar asegurado como un innegociable, es precisamente aquello por lo que sigue luchando la población campesina: la vida. 


\section{Notas}

${ }^{1}$ Referencia de archivo documental en el que el oidor Luís Henríquez exponía la ferocidad de las tribus asentadas en las riberas del río Magdalena y sus afluentes. Tomado de: (Moncada, A., 1993: 72).

${ }^{2}$ La continua referencia y apropiación del movimiento de los Comuneros y de José Antonio Galán como estandartes de la luchas emancipatorias cubre un amplio espectro que va desde la adopción de grupos guerrilleros como el Ejército Nacional de Liberación al fundar frentes con el nombre del líder hasta el nacimiento de movimientos cívicos urbanos como Comuneros 81.

${ }^{3}$ No se puede desconocer que las formas de producción semiservil y colonial de la hacienda no fueron homogéneas. En algunas regiones del país imperó la hacienda de estilo ganadero, especialmente en la costa Atlántica, en otras, fue una hacienda de trapiches, molienda y procesamiento de caña de azúcar; en otras lo imperante fue un tipo de hacienda cafetera. En cada una de éstas las relaciones de trabajo o de producción ponían un énfasis distinto en la clase de remuneración para los campesinos e indígenas: desde el grado más servil de la relación de trabajo con el hacendado, como el terraje en los antiguos resguardos indígenas, hasta un grado casi autónomo de relación contractual como la aparcería. Ver al respecto, (González, 1985) y (Arango et al, 1987).

${ }^{4}$ Ver al respecto, (Pérez Martínez, 2004) o (Mondragón, 2002) y (Suhner, 2002: 138). La ley estipulaba textualmente: "que si en el término de diez años no se explota (la tierra), ésta sería revertida en forma automática al Estado.” Tomado de: (Pérez Martínez, 2004:71).

${ }^{5}$ Ver (Mondragón, 2002:.28-29). En palabras del propio Mondragón: “Conquistas logradas fueron destruidas, por ejemplo fueron desbaratados los baluartes de Córdoba y el Cabildo y Resguardo de Ortega y Chaparral que habían sido reconstituidos en 1937. En el Cauca se desconocieron nuevamente los títulos indígenas y se agudizó el terraje. En Tubará (Atlántico) dejó de funcionar el Cabildo indígena.”

${ }^{6}$ La afirmación anterior está desprovista de cualquier carácter subjetivista puesto que la lucha por la desarticulación y desorganización de las asociaciones campesinas llegó hasta el punto de aplicar, por parte de la elite terrateniente, estrategias como la del envenenamiento de altos dirigentes como fue la muerte de José Gonzalo Sánchez, presidente de la Federación Campesina e Indígena, para 1952.

${ }^{7}$ Para un desarrollo más extenso de la evolución de la OFP y la transformación de sus demandas, ver (García, M., 2006: 271-276).

${ }^{8}$ Ramírez y Osorio, 2004, 2007.

${ }^{9}$ Como sucede a menudo con las representaciones y las significaciones culturales, la identidad campesina será utilizada de diferentes maneras y desde valores contrapuestos. Esta recurrencia a lo campesino está en la raíz misma del conflicto colombiano y del uso que le han dado los actores armados, que desde las guerrillas izquierdistas de los años 60 hasta los paramilitares de los 90 y sus organizaciones fachadas, se han entendido como parte integrante de esa identidad. Ver para complementar esta reflexión, (Archila, M., 2006: 497502). Sin embargo, tal vez sería conveniente movernos hacia reflexiones más abiertas como las de (Salgado y Prada, 2002), en las que esta recurrencia pluralista hacia la identidad 
campesina está mostrando más bien es un interesante proceso de formación cosmopolita, en los que los espacios campesinos están siendo atravesados por múltiples actores, tipos de capital y organizaciones nacionales e internacionales.

${ }^{10}$ Reconstrucción de los primeros hechos de la organización aportados por los líderes fundadores Simón Palacios y Ramón Córdoba, mediante entrevistas realizadas en el mes de agosto de 2009, corregimiento de La India, Santander, Colombia.

${ }^{11}$ Dentro de una de las estrategias aplicadas por el Ejército en la región del Carare específicamente estuvo la de la implantación de una carnetización para todos los pobladores, llamada tránsito libre, la cual implicaba el traslado y presentación de cada campesino al batallón Rafael Reyes cada 15, 20 o 30 días, con el fin de ser refrendado dicho carnet y así tener el control de la población y de los elementos externos que llegaban o se movían en la zona. Prácticamente todos las fuentes orales recuerdan aún con dolor aquella época que duró hasta el año 1985, donde el no estar a "paz y salvo” acarreaba la detención y posterior tortura. Ver igualmente, (Hernández, 2004 ), (Galvis, 2005: 175) .

${ }^{12}$ Entrevista realizada por Enrique Mendoza al líder campesino Luís Carlos Restrepo, Junio de 2009.

${ }^{13}$ Entrevista realizada al líder fundador de la ATCC don Ramón Córdoba, Agosto de 2009.

${ }^{14}$ Testimonio tomado de (Arenas, 2009: 129).

${ }^{15}$ Entrevista realizada a don Ramón Córdoba, líder fundador de la ATCC. Agosto de 2009.

${ }^{16}$ Entrevista realizada a don Simón Palacios, líder fundador de la ATCC y asociado. Agosto de 2009.

${ }^{17}$ Recordemos que la más cercana antecesora de las organizaciones campesinas en Colombia fue la Asociación Nacional de Usuarios Campesinos (ANUC). De carácter nacional, la ANUC fue perdiendo presencia en las regiones y fue dando paso a otro tipo de organizaciones más pequeñas, pero con mayor unidad.

${ }^{18}$ Tomado de (García, A., 1996: 198).

${ }^{19}$ Todos estos logros fueron corroborados por los dirigentes más antiguos entrevistados en la experiencia de campo realizada, tales como don Simón Palacios, don Ramón Córdoba, Javier Mosquera y Norberto Viana Carrasquilla. Así mismo, el texto de Alejandro García da prueba de los logros de la organización campesina a partir del balance hecho desde un tiempo más cercano a la fundación de la ATCC, ver, (García, A., 1996).

${ }^{20}$ Entrevista realizada a Cristina Serna, líder de la ATCC y exdirectiva. Septiembre de 2009.

${ }^{21}$ En todas las entrevistas elaboradas y en todo el material recopilado resalta el elemento de diálogo como último recurso para frenar la violencia que estaba viviendo la población, en el que se tenía presente el riesgo y las posibilidades de generación de más violencia por incomprensión de los actores armados. El alto nivel de tensión generado por las discusiones y por la exposición de las argumentaciones fue un índice del, si se puede llamar así, heroísmo de los líderes campesinos. 
${ }^{22}$ Entrevista realizada a Javier Mosquera, asociado y lanchero de la ATCC. Agosto de 2009.

${ }^{23}$ Entrevista realizada a Cristina Serna, ex dirigente de la ATCC. Septiembre de 2009.

${ }^{24}$ Observación aportada en entrevista realizada conjuntamente a la directora de la Junta de Acción Comunal de La India Fanny Isabel Leal y al asociado Fernando Aguilar, Agosto de 2009.

${ }^{25}$ Entrevista realizada a la líder Cristina Serna. Septiembre de 2009.

${ }^{26}$ Cabe señalar que esta forma de resolución de conflictos, así como la experiencia de construcción de paz de la ATCC, niega de entrada cualquier metodología o sistematización estructural que pueda constituirse en un recetario o molde aplicable a situaciones de violencia. Estas "instancia de defensa vital" frente al asesinato inminente fueron sacadas de las entrevistas realizadas a Javier Mosquera, asociado histórico de la ATCC, Agosto de 2009 y a Cristina Serna, líder y exdirigente de la ATCC, Septiembre de 2009.

${ }^{27}$ Estos proyectos quedaron plasmados en el documento titulado: "Plan de desarrollo del Corregimiento de la India. Por el derecho a la vida, la paz y el trabajo.” Dirigido hacia el beneficio de unas 3 mil familias campesinas de la región.

${ }^{28}$ Estos puntos son un resumen del documento Plan de desarrollo del Corregimiento de La India.

${ }^{29}$ Para el año 2003, la asociación hizo la respectiva reforma de los estatutos, donde se definió que: "un desmovilizado, de cualquier grupo armado, luego de 5 años de mostrar buen comportamiento acorde a los principios de la ATCC, si quiere ser socio, lo puede ser divinamente. Y si se le ve perfil puede ser directivo de la ATCC. Hay ahí una posibilidad para ellos, pero después de haberlo demostrado. Una persona puede después de 2 años de haber dejado los (cultivos) ilícitos y mostrar buen comportamiento, puede ser admitido como socio de la ATCC.” Entrevista realizada a Mauricio Hernández, vicepresidente de la ATCC. Agosto de 2009.

${ }^{30}$ Entrevista a don Ramón Córdoba, líder fundador y expresidentes de la ATCC. Agosto de 2009.

${ }^{31}$ La parte productiva ha sido reconocido por la mayoría de personas como la dimensión más débil de la asociación. Incluso en algunos casos se ha llegado a afirmar que: "pareciera como si a la ATCC no le gustara la plata." o "en una asociación en que nos toca pedir limosneado para un pasaje estamos jodidos.” Entrevista a Fernando Aguilar, asociado de la ATCC. Agosto de 2009.

${ }^{32}$ Entrevista realizada a Mauricio Hernández, vicepresidente de la ATCC, Agosto de 2009.

${ }^{33}$ Información proporcionada por la docente, socia de la ATCC y fundadora del colectivo de mujeres Silvia Duzán, Claudia Becerra, en entrevista personal. Agosto de 2009.

${ }^{34}$ Entrevista colectiva realizada a Erika Arias y Braulio Mosquera, directiva de Asodecar, Septiembre de 2009. 


\section{Bibliografía}

Archila, M., (2006), “Las identidades en el Magdalena Medio”, en Archila, Bolivar, et al, Conflictos, poderes e identidades en el Magdalena Medio, 1990-2001, Colciencias-Cinep, Bogotá.

Arango, M., et al (1987), Economía campesina y políticas agrarias en Colombia: una evaluación del programa D.R.I, Universidad de Antioquia, Medellín.

Arenas, Claudia Marcela (2009), La India, territorio de paz y reconciliación. Poblamiento, conflicto armado y proceso de reparación colectiva, 1968-2009, Tesis de grado Licenciatura en Historia, Universidad Industrial de Santander, Bucaramanga.

Bejarano, Jesús Antonio (1987), Campesinado, luchas agrarias e historia social: notas para un balance historiográfico, en Ensayos de historia agraria colombiana, CEREC: Bogotá.

Cante, Freddy (Ed.) (2007), Poder social. Algunas posibilidades en Colombia. Universidad del Rosario-CEPI, Bogota.

Calderón, Fernando (1997), “Los movimientos sociales en América Latina: entre la modernización y la construcción de la identidad”, En Quesada, Fernando, (Ed), Filosofía política I. Ideas políticas y movimientos sociales, Trotta, Madrid.

Fajardo, Darío (2002), “Tierra, poder político y reformas agraria y rural”, en Cuadernos Tierra y Justicia $\mathrm{N}^{\circ} 1$, Bogotá.

Ferreira, Adriana, (2008), A 20 años del asesinato de los líderes fundadores de la ATCC, en www.elfrente.com.co/index.php?...atcc

García, Alejandro (1996), Hijos de la violencia. Campesinos de Colombia sobreviven a "golpes” de paz. Los libros de la Catarata, Madrid.

García Naranjo, Federico (s/f), El marqués de San Jorge y la participación de la élite santafereña en la independencia de la Nueva Granada, en: Orvis Incognitus. Avisos y Legajos del Nuevo Mundo. Universidad Complutense de Madrid. XII Congreso de la AEA, en: http://www.americanistas.es/biblo/ textos/c12/c12-103.pdf

García, M. G. (2006), Barrancabermeja: ciudad en permanente disputa, en: Archila, M. et al, Conflictos, poderes e identidades en el Magdalena Medio, 1990-2001, Colciencias-Cinep: Bogotá.

Galvis, Santiago (2005), “El Carare y el espacio social. Una aproximación al proceso histórico social de la construcción del territorio”, Maguaré, $\mathrm{N}^{\circ}$ 19, UNC, Bogotá. 
González Cassanova, P.(Coord.) (1985), Historia política de los campesinos latinoamericanos, Vol 3, Siglo XXI, México.

Hernández Delgado, E. (2006), Resistencia civil, artesana de paz. Experiencias indígenas, afrodescendientes y campesinas, Universidad Javeriana, Bogotá.

Moncada, A. (1993), Las colonizaciones en el Magdalena Medio Santandereano (Provincia de Mares). Documento de trabajo, UIS, Bucaramanga.

Mondragón, Héctor (2002), La organización campesina en un ambiente de terror, (s/ed), Bogotá.

Ídem, ¿Reforma agraria o mercado de tierras?, Colombia, en: www.acantioquia.org

Pérez Martínez, Manuel Enrique (2004), “La conformación territorial en Colombia: entre el conflicto, el desarrollo y el destierro”, en: Cuadernos de desarrollo rural, $\mathrm{N}^{\circ}$ 51, Universidad Javeriana, Bogotá.

Pinilla, Elmer, Pipatón. El cacique de los talones alados, en: http:// www.elaleph.com/libro/Pipaton-El-cacique-de-los-talones-alados-deElmer-Pinilla-Galvis/163269/

Romero Medina, Amanda (1994), Magdalena Medio. Luchas sociales y violaciones de los derechos humanos, Corporación AVRE, Barrancabermeja.

Salgado, Carlos y Prada, Esmeralda (2000), Campesinado y protesta social en Colombia. 1980-1995, Cinep, Bogotá.

Suhner, S. (2002), Resistiendo al olvido. Tendencias recientes del movimiento social y de las organizaciones campesinas en Colombia, UNRISD, Bogotá.

Tobasura, Isaías (2006), "Reivindicaciones y repertorios de acción del movimiento campesino en Colombia en los albores del siglo XXI”, ponencia presentada en el VII Congreso Latinoamericano de Sociología Rural, 20-24 de Noviembre de 2006, Quito.

Recibido: 24.01.2011

Aceptado: 03.03.2011 